\title{
Effect of Tai Chi Exercise on Immune Function in Middle-aged and Elderly Women
}

\author{
Jing Liu',2*, Peijie Chen ${ }^{3}$, Ru Wang ${ }^{3}$, Yonghong Yuan ${ }^{4}$, and Chunying $\mathrm{Li}^{5 *}$ \\ ${ }^{1}$ Department of Martial Arts, Shanghai University of Sport, Shanghai 200438, China \\ ${ }^{2}$ Department of Psychology, School of Kinesiology, University of Michigan, Ann Arbor, MI, 48109, USA \\ ${ }^{3}$ Department of Sports Medicine, Shanghai University of Sport, Shanghai 200438, China \\ ${ }^{4}$ Department of Sports Leisure, Shanghai University of Sport, Shanghai 200438, China \\ ${ }^{5}$ Department of Biochemistry \& Molecular Biology, Wayne State University School of Medicine, Detroit, Michigan 48201, USA
}

\begin{abstract}
Objective: The purpose of this study was to investigate the effect of Tai Chi (TC) exercise on immune functions among middle-aged and elderly women, and to evaluate the relationship between immune modulation of Natural Killer T (NKT) cells and Dendritic Cells (DCs) and T Helper (Th) $1 /$ Th2 immune response.

Methods: Sixty healthy middle-aged and elderly women were randomly assigned into 2 groups: Tai Chi (TC) group $(n=30)$ and control $(C O N)$ group $(n=30)$. Subjects in TC group participated in TC exercise for 6 months, 60 minutes a day, four times a week. Meanwhile, subjects in CON group maintained their normal physical activity levels during the whole study period. Peripheral blood samples were collected right before, and after 4 and 6 months of the exercise program, and the sampled were analyzed within 24 hours after collection.
\end{abstract}

Results: After the 6 -month TC exercise program, the percentage of $C D 4^{+} \mathrm{T}$ lymphocytes, the $\mathrm{CD} 4^{+}: \mathrm{CD} 8^{+}$ratio, and the percentage of NK and NKT cells in TC group significantly increased $(p<0.05)$. The percentage of interferon- $Y$ (IFN-y) producing T cells increased significantly after 4 months $(p<0.01)$ and 6 months $(p<0.05)$ of exercise. The percentage of interleukin-4 (IL-4) producing T lymphocytes also demonstrated an increase after 4 months $(p<0.05)$ and 6 months $(p>0.05)$ of exercise. The percentage of CD123+ DCs and CD11 $c^{+}$DCs also significantly increased after the 6-month program $(p<0.01)$, with the percentage of $C D 11 c^{+}$cells increasing much more dramatically than $\mathrm{CD}_{123^{+}}$ DCs. However, the CON group did not show any significant changes in these parameters.

Conclusion: Regular TC exercise favors the development of Th1 immune responses in middle-aged and elderly women. TC-induced changes in Th1 and Th2 immune responses are associated with the immune modulation of NKT cells and DCs and their reciprocal interactions.

Keywords: Physical activity; Immunology; Immunosenescence; Aging; Female

\section{Introduction}

Immunosenescence is the steady degeneration of the immune system that occurs with age in humans and animals [1]. Multiple aspects of the immune response are severely disregulated by aging, among which the $\mathrm{T}$ cell immune response is the most dramatically affected. T cell-mediated production of cytokines Interleukin (IL)-2 and Interferon (IFN)- $\gamma$ decreases significantly with age. The amount of IFN- $\gamma$ decreases along with the activity of T Helper 1 (Th1) cells and the amount of IL-4 and IL-10 increases along with the activity of T Helper 2 (Th2) cells $[2,3]$, resulting in a decreasing ratio of Th1/Th2 in elderly people. The decrease in the numbers of Natural Killer (NK) cells and Natural Killer T (NKT) cells contributes to the deleterious immune response in the elderly, and the number of myeloid Dendritic Cells (DCs) also progressively declines with age [4].

Aging is also associated with decreased physical activity. Exercise can profoundly influence health, and there is mounting evidence that the mechanisms behind these effects are related, in part, to the impact of exercise on immune function [5]. It has been shown that the numbers of circulating $\mathrm{T}$ cells and their functions are influenced by brief periods of exercise [6,7]. Hinton et al. [8] reported significant changes in the composition of the total lymphocyte cultures immediately postexercise: increased numbers of $\mathrm{CD}^{+} 6^{+} \mathrm{NK}$ cells and $\mathrm{CD}^{+} \mathrm{T}$ cells and decreased numbers of T-helper cells $\left(\mathrm{CD}^{+}\right)$, in male endurancetrained runners after an interval running session of $15 \times 1$-min intervals at $95 \% \mathrm{VO}_{2}$ max. A decrease in mitogen-stimulated $\mathrm{T}$ cell proliferation and $\mathrm{T}$ cell production of IL- 2 and IFN- $\gamma$ was reported immediately after acute, intensive exercise [9]. In fact, the volume of exercise has been shown to be a critical element in inducing a positive or negative effect on the immune response $[5,10]$. It has been shown that moderate exercise enhances $\mathrm{T}$ cell function and decreases respiratory infections [11]. Although many components of the immune system are known to exhibit various changes depending on the stage and type of exercise, the long-term effects of regular moderate exercise on immune responses remain incompletely understood.

Tai Chi (TC) is a traditional Chinese martial art with a long history. It usually consists of TC Chuan and TC Weapon (for example, TC Sword, TC Spear, TC Broa dsword). TC has gained popularity in Western countries in recent years for its recognized positive effects on health in the elderly [12]. TC incorporates slow-moving, gentle physical activity, balance, and weight shifting, with meditation, relaxation, deep

*Corresponding authors: Jing Liu, Ph.D., Department of Martial Arts, Shangha University of Sport, 588 Qing Yuan Huan Road, Shanghai 200438, China, E-mail: liujing_j3@163.com

Chunying Li, Ph.D., Department of Biochemistry \& Molecular Biology, Wayne State University School of Medicine, 540 E. Canfield, 5312 Scott, Detroit, MI 48201 USA, Tel: (313) 577-4182; Fax: (313) 577-2765; E-mail: cl@med.wayne.edu, cl@med.wayne.edu

Received September 27, 2012; Accepted November 09, 2012; Published November 11, 2012

Citation: Liu J, Chen P, Wang R, Yuan Y, Li C (2012) Effect of Tai Chi Exercise on Immune Function in Middle-aged and Elderly Women. J Sports Med Doping Stud 2:119. doi:10.4172/2161-0673.1000119

Copyright: @ 2012 Liu J, et al. This is an open-access article distributed under the terms of the Creative Commons Attribution License, which permits unrestricted use, distribution, and reproduction in any medium, provided the original author and source are credited. 
breathing, and imagination. Reported benefits of TC include increased balance and decreased incidence of falls, increased strength and flexibility, reduced pain and anxiety, improved self-efficacy, improved sleep, and enhanced cardiopulmonary function [12]. TC has also been shown to significantly increase the ratio of $\mathrm{CD}^{+} v s$. $\mathrm{CD} 8^{+}$, significantly increase $\mathrm{CD}^{+} / \mathrm{CD} 25^{+}$regulatory $\mathrm{T}$ cell number [13] reduce the levels of HbAlc in type II diabetes and enhance the Th1 response [14] and increase varicella-zoster virus specific cell-mediated immunity [15], significantly increased the numbers and activity of natural killer cells in the peripheral blood [3]. To our knowledge, there haven't been any studies as to whether TC could promote the amelioration of the ageinduced Th1/Th2 immune imbalance.

The purpose of this study was to investigate the effect of TC on the subsets of T cells, NK cells, NKT cells and DCs, and the cytokines IFN- $\gamma$ and IL-4 producing T cells, in aged 50-65 women who had practiced TC for six months. Our hypothesis was that TC induces a Th1-type immune response in elderly people, ameliorating the age-induced immune

\begin{tabular}{|l|l|l|l|l|}
\hline & \multicolumn{2}{l|}{ CON group $(\mathrm{N}=30)$} & \multicolumn{2}{l|}{ TC group $(\mathrm{N}=30)$} \\
\cline { 2 - 5 } & Pre & Post & Pre & Post \\
\hline Age $(\mathrm{yr})$ & $55 \pm 2.74$ & - & $54 \pm 3.54$ & - \\
Body Weight $(\mathrm{kg})$ & $62.14 \pm 12.77$ & $62.33 \pm 11.86$ & $64.41 \pm 10.09$ & $63.93 \pm 11.26$ \\
Height $(\mathrm{cm})$ & $165.28 \pm 1.95$ & $165.42 \pm 1.87$ & $164.33 \pm 2.09$ & $164.97 \pm 1.77$ \\
BMI $\left(\mathrm{kg} / \mathrm{m}^{2}\right)$ & $23.96 \pm 0.87$ & $23.34 \pm 0.93$ & $24.19 \pm 0.79$ & $23.99 \pm 0.68$ \\
Body Fat $(\%)$ & $28.82 \pm 7.61$ & $28.72 \pm 6.34$ & $29.07 \pm 6.33$ & $29.02 \pm 5.69$ \\
\hline
\end{tabular}

Table 1: Characteristics of all subjects in both CON and TC groups before and after 6 months of TC exercise training. CON group: control group; TC group: Tai Chi exercise group; Pre: pre-exercise program; Post: 6-month after exercise program; BMI: body mass index. imbalance. By evaluating the relationships between TC exercise and T lymphocyte immune function, we sought to elucidate the role that TC exercise plays in reversing the age-associated imunosenescence.

\section{Materials and Methods}

\section{Subjects}

Sixty women, aged 50-65, were recruited by advertising for the study, and randomly divided into 2 groups: Tai Chi (TC) exercise group $(n=30)$ and non-exercise control $(\mathrm{CON})$ group $(n=30)$. Table 1 shows the physical characteristics of the study subjects, and both groups were of similar age and body composition. Body mass and Body Mass Index (BMI) did not demonstrate any significant changes during the whole study period in either TC group or CON group. Exclusion criteria included angiocardiopathy (cardiopulmonary illness), autoimmune disorder, metabolic disorder, malignancies actively being treated with chemotherapy, hormone replacements (such as the use of corticosteroids), and acute illness from infection, and major surgery during the preceding 6 months. All subjects had no TC training experience before. Written informed consent was obtained from all participants upon enrollment, and the protocol was reviewed and approved by the institutional review board of Shanghai University of Sport. The subjects in the CON group were instructed not to participate in any formal exercise but simply to maintain their normal levels of physical activity as usual for the whole 6-month study period, and they kept diaries to record their daily activities.

\section{TC exercise program}

All subjects in TC group participated in TC Chuan (24 forms;
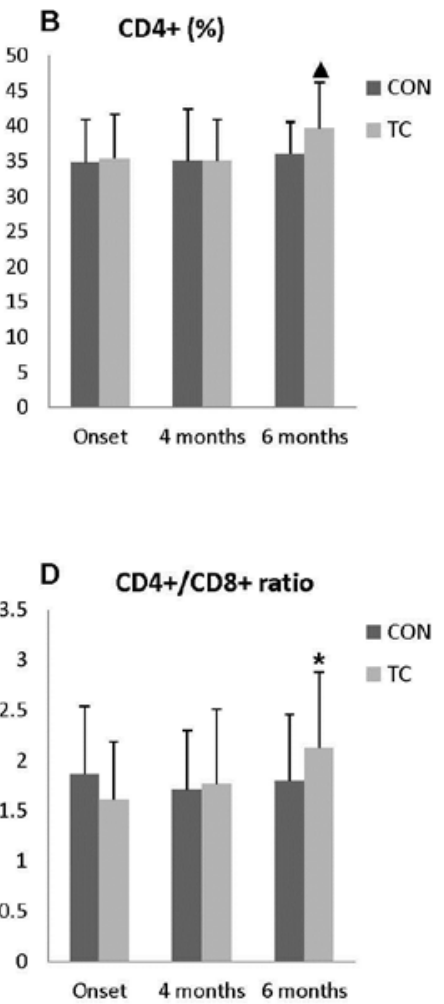

Figure 1: Comparison of the percentages of T lymphocyte $\mathrm{CD} 3^{+}(\mathbf{A})$, and their subsets $\mathrm{CD} 4^{+}(\mathrm{B})$ and $\mathrm{CD} 8^{+}(\mathbf{C})$ in the peripheral blood, as well as $\mathrm{CD} 4^{+} / \mathrm{CD} 8^{+}$ratio (D) at the onset, 4 months and 6 months during the study period in control (CON) group and Tai Chi (TC) exercise group. Data are presented as Mean \pm SEM. $P$ values were analyzed by Student's paired $t$-test ( $n=3$ subjects per group). * $p<0.05$ as compared with onset of the same group $p<0.05$ as compared with 4 months of the same group. 
Supplementary figure 1 for TC techniques) and TC Sword (42 forms) exercise for 6 months, 4 sessions a week. They were supervised and instructed by an experienced TC teacher who has practiced TC for 18 years. Each TC session lasted 60 minutes consisting of a 10 minutes warm up, a 40 minutes practice, and a 10 minutes cool down. The subjects in TC group spent 3 months in learning and practicing all forms of TC Chuan and TC Sword, and then continued to practice for another 3 months. All TC subjects kept diaries to record details.

\section{Blood sampling and analysis}

Blood sampling: At the onset, 4-month, and 6-month during the study period, peripheral venous blood $(5 \mathrm{ml})$ of each subject in both groups was collected in an anticoagulant heparin tube. Blood samples were analyzed within 24 hours of collection. Blood was collected between 7 am- 9 am in the morning after a 12 hours overnight fast (only water was allowed). On the day of blood collection, subjects did not carry out any TC exercise. All subjects refrained from any exercise for at least 24 hours before the blood collection/sampling.

\section{Analysis of T cell subset, NKT cells, and NK cells}

Flow cytometric analysis for T cells: Peripheral blood (100 l) was incubated with anti-human CD4-fluorescein isothiocyanate (FITC), anti-human CD8-phycoerythrin (PE), as well as anti-human CD3peridinin chlorophyll protein (PerCP)-Cy5 antibodies (Immunotech Co.) in the dark for 15 minutes. Then haemolysis fixative agent $(0.5$ $\mathrm{ml}$ ) (Beckman Coulter) was added for another 10 minutes, followed by the addition of Isoton II diluent $(0.5 \mathrm{ml})$ (Beckman Coulter). $\mathrm{CD}^{+}$, $\mathrm{CD}^{+}$, and $\mathrm{CD}^{+}$cells were measured using fluorescence detection by flow cytometry.

Flow aytometric analysis for NK/NKT cells: Peripheral blood (100 ul) was stained with anti-human CD3-FITC, anti-human CD16-PE, and anti-human CD56-PE antibodies (Beckman Coulter, California, USA). After staining, red blood cells were lysed with OptiLyse C Lysing Solution (Beckman Coulter). Finally, cells were analyzed using a Coulter EPICS XL Flow Cytometer (Beckman Coulter) with System IITM software. NK cells were defined as $\mathrm{CD}^{-} \mathrm{CD} 16^{+} \mathrm{CD} 56^{+}$cells, and $\mathrm{NKT}$ as $\mathrm{CD}^{+}{ }^{+} \mathrm{CD} 16^{+} \mathrm{CD} 56^{+}$cells [16].

\section{Analysis of IFN- $\gamma$ and IL-4 producing $\mathrm{CD}^{+} \mathrm{CD}^{+} \mathrm{T}$ cells}

Ten $\mu \mathrm{l}$ of PMA $(1 \mu \mathrm{g} / \mathrm{ml}), 8 \mu \mathrm{l}$ of ionomycin $(50 \mu \mathrm{g} / \mathrm{ml})$ and 6.8 $\mu \mathrm{l}$ of monensin fluid $(0.1 \mathrm{mg} / \mathrm{ml}$; Sigma Chemical Co. $)$ were added to peripheral blood $(200 \mu \mathrm{l})$ along with RPMI-1640 media (200 $\mu \mathrm{l}$ ), and incubated for 4 to 6 hours at $37^{\circ} \mathrm{C}$ in a $5 \% \mathrm{CO} 2$ incubator. Monoclonal anti-CD3-PerCP $(20 \mu \mathrm{l})$ and anti-CD4-FITC antibodies $(20 \mu \mathrm{l}$; Beckman Coulter) were then added and the mixture was incubated for another 15 minutes. After the incubation, cell suspension of each sample was divided into three 100-l aliquots, and all samples were treated with fixation/permeabilization reagents according to the manufacturer's instructions (Beckman Coulter). Intracellular cytokines in each aliquot were stained using PE-conjugated mAbs against IL-4, IFN- $\gamma$, or an isotype control (Beckman Coulter) for 30 minutes. The samples were washed with PBS and the supernatant was discarded. The cell pellet was resuspended in PBS and analyzed by flow cytometry. All incubations (except PMA-activation and incubation) were performed at room temperature in the dark.

\section{Analysis of $\mathrm{CD} 123^{+}$and $\mathrm{CD} 1 \mathrm{c}^{+}$dendritic cells by direct immunofluorescence staining of whole blood}

Monoclonal antibodies: PE-conjugated anti-IL-3 receptor $a$ chain (CD123), PE-conjugated anti-CD11c, PerCP-conjugated anti-HLA-
DR, and FITC-conjugated lineage cocktail 1 (lin 1), as well as PE- and PerCP-conjugated isotype control murine $\mathrm{mAbs}$ were obtained from $\mathrm{BD}$ (San Jose, CA). The lin 1 contains monoclonal antibody clones against CD3 (T cells), CD14 (monocytes/macrophages), CD16 (natural killer cells), CD19 (B cells), CD20 (B cells), and CD56 (natural killer cells). Sensitive detection of DCs was achieved by exclusion of cells positive for CD3, CD14, CD16, CD19, CD20, or CD56 using Lineage Cocktail 1 (FITC-conjugated Ab mixture against CD3, CD14, CD16, CD19, CD20, and CD56). Thereafter, myeloid and lymphoid DCs (DC1s and DC2s, respectively) were detected using $\mathrm{PE}$-conjugated $\mathrm{Ab}$ against $\mathrm{CD} 11 \mathrm{c}$ and CD123, respectively.

Flow cytometric analysis: Peripheral blood cells obtained from the subjects were analyzed by three-color flow cytometry. To minimize selective cell loss during the preparation procedure, the cells were first stained with $\mathrm{mAbs}$ followed by lysing the erythrocytes. Briefly, aliquots $(100 \mu \mathrm{l})$ of peripheral blood were incubated with a mixture of antilin mAbs (BD Biosciences), a PerCP-conjugated anti-HLA-DR mAb, and either a PE-conjugated anti-CD11c mAb to detect myeloid DC or a PE-conjugated anti-CD123 mAb to detect plasmacytoid DC, or a PE-conjugated isotype control (BD Biosciences) in the dark at room temperature for $15 \mathrm{~min}$ (Supplementary table 1). Then $2 \mathrm{ml}$ of FACS lysing solution (BD) was added, vortexed, and incubated for 10 minutes to lyse the erythrocytes. The mixture was centrifuged at $300 \times \mathrm{g}$ for 5 minutes, and the supernatant was discarded. The mixture was then vortexed gently with $1 \mathrm{ml}$ of wash buffer, centrifuged again as described above, and the supernatant was discarded. Thereafter, the mixture was vortexed and resuspended in $300 \mu$ of $1 \%$ paraformaldehyde for $10 \mathrm{~min}$, and then washed and analyzed on a flow cytometer. Identical flow cytometric settings were used for the acquisition of all samples enabling the expression of cell surface molecules on different samples to be directly compared. All incubations were performed at room temperature in the dark. DCs were defined as the cells positive for PerCP-conjugated anti-HLA-DR $\mathrm{mAb}$ and negative for FITCconjugated lin 1 . Anti-CD11c or anti-CD123 mAb conjugated with PE was used for further identification of the $\mathrm{mDC}$ and $\mathrm{pDC}$ subsets.

\section{Statistical analysis}

All data were expressed as means \pm SEMs, and $p<0.05$ was set as the criterion for significance. The Statistical Package for Social Sciences (SPSS Inc, USA; version 12.0) was used for statistical analysis. Data were analyzed using one-way Analysis Of Variance (ANOVA), and the independent samples t-tests were applied to assess differences between control group and TC group before exercise program. Paired-samples $t$-tests were only used to assess differences of variables between preexercise and 4-month, as well as between pre-exercise and 6-month.

\section{Results}

\section{Effect of TC exercise on T lymphocytes and their subsets}

As shown in Figure 1, the percentages of $\mathrm{T}$ lymphocytes $\left(\mathrm{CD}^{+}\right)$and their subsets $\left(\mathrm{CD} 4^{+}\right.$and $\left.\mathrm{CD} 8^{+}\right)$in the peripheral blood before exercise program (at onset) did not show any significant inter-group differences between CON and TC groups. Six-month TC exercise program significantly increased the percentage of $\mathrm{CD}^{+} \mathrm{T}(\mathrm{Th})$ lymphocytes and the $\mathrm{CD}^{+}: \mathrm{CD}^{+}$ratio $(p<0.05$; Figures $1 \mathrm{~B}$ and $1 \mathrm{D})$, while no significant change in the percentages of $\mathrm{CD}^{+}$or $\mathrm{CD}^{+} \mathrm{T}$ cells was observed (Figures 1A and 1C). Within the TC exercise group, the difference was significant in the $\mathrm{CD}^{+}: \mathrm{CD}^{+}$ratio at 6 -month of $\mathrm{TC}$ exercise compared with the ratio at the onset $(p<0.05$; Figure 1D). There was also a significant difference in the percentage of $\mathrm{CD} 4^{+} \mathrm{T}$ lymphocytes at 

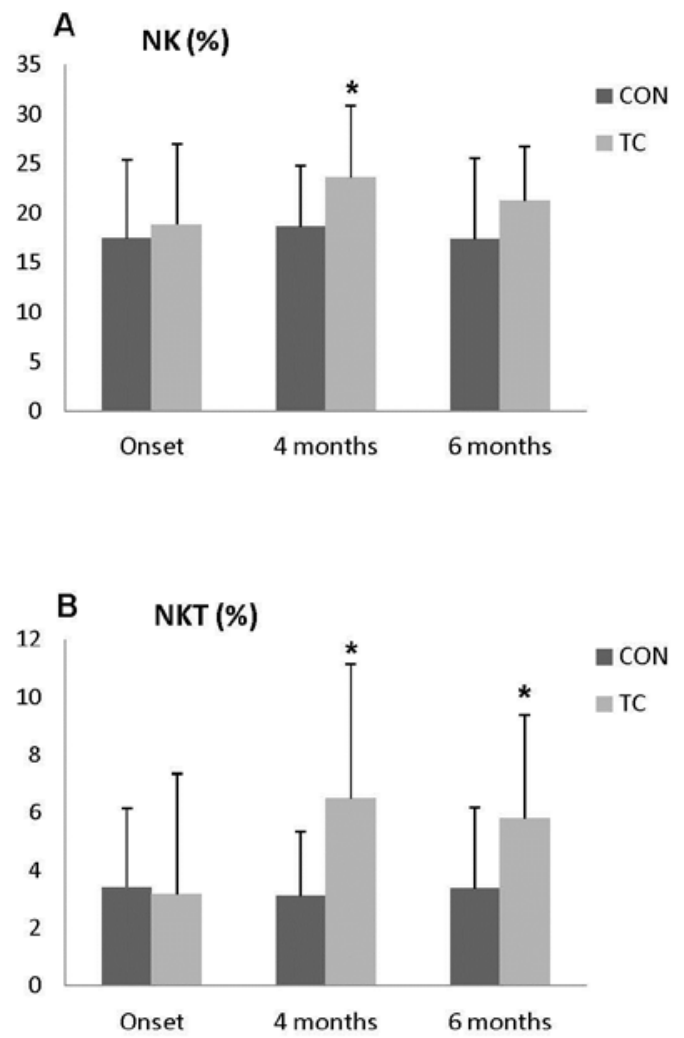

Figure 2: Comparison of NK (A) and NKT (B) cell percentages in the peripheral blood at the onset, 4 months and 6 months during the study period in control (CON) group and Tai Chi (TC) exercise group. Data are presented as Mean \pm SEM. * $p<0.05$ as compared with onset of the same group.

6-month compared with at 4 -month of TC exercise ( $p<0.05$; Figure 1B). However, the percentages of $\mathrm{T}$ lymphocytes $\left(\mathrm{CD}^{+}\right)$and their subsets $\left(\mathrm{CD}^{+}\right.$and $\left.\mathrm{CD} 8^{+}\right)$in $\mathrm{CON}$ group did not demonstrate any changes during the whole study period (onset; 4 months; and 6 months).

\section{Effect of TC exercise on NK and NKT cells}

Figure 2 shows the changes in the percentages of NK cells and NKT cells in the peripheral blood in both CON and TC groups. The percentages of NK cells and NKT cells before exercise program (at onset) did not show any inter-group differences between CON and TC groups. Following TC exercise program, the percentages of both NK and NKT cells significantly increased at 4 months compared with at the onset $(p<0.05$; Figures $2 \mathrm{~A}$ and $2 \mathrm{~B})$. At 6 months of TC exercise program, the percentages of both NK and NKT cell decreased slightly compared with at 4-month, but the percentage of NKT cells at 6-month was still significantly higher than at the onset $(p<0.05$; Figure $2 \mathrm{~B})$. The percentages of NK cells and NKT cells in CON group did not demonstrate any significant changes during the whole study period (onset; 4 months; and 6 months).

\section{Effect of TC exercise on cytokines IL-4 and IFN- $\gamma$ producing $\mathrm{CD}^{+} \mathrm{T}$ cells}

Figure 3 shows the changes in the percentages of IFN- $\gamma$ producing $\mathrm{CD} 4{ }^{+} \mathrm{T}$ cells (Th1) and IL-4 producing $\mathrm{CD} 4{ }^{+} \mathrm{T}$ cells (Th2) in both CON and TC groups. The percentages of both IFN- $\gamma$ and IL-4 producing $\mathrm{CD}^{+} \mathrm{T}$ cells before exercise program (at onset) were not significantly different between CON and TC groups (Figure 3). However, TC exercise program significantly increased both IFN- $\gamma$ and IL- 4 producing CD $4^{+}$ $\mathrm{T}$ cells (Figure 3 ). There was significant difference in the proportion of IFN- $\gamma(p<0.01$; Figure 3A) and IL-4 ( $p<0.05$; Figure 3B) producing T cells at 4-month of TC exercise compared with at the onset. IFN- $\gamma$ producing $\mathrm{T}$ cells also demonstrated a significantly higher percentage at 6-month than at the onset $(p<0.05$; Figure $3 \mathrm{~A})$. The percentages of IFN- $\gamma$ and IL- 4 producing $\mathrm{CD}^{+} \mathrm{T}$ cells in CON group did not show any significant changes during the whole study period (onset; 4 months; and 6 months).

\section{Effect of TC exercise on $\mathrm{CD} 123^{+} \mathrm{DCs}^{\mathrm{D}}$ and $\mathrm{CD} 11 \mathrm{c}^{+}$dendritic cells}

As shown in figure 4, the percentages of both $\mathrm{CD}_{123}$ (plasmacytoid) DCs and CD11c ${ }^{+}$(myeloid) DCs before TC exercise program (at onset) were not significantly different between CON and TC groups. However, after the 6 months of TC exercise program, the percentage of both CD123+ (plasmacytoid) DCs and CD11 ${ }^{+}$(myeloid) DCs significantly increased (Figure 4 ). There was significant increase in the percentages of CD11 $c^{+}$DCs $(p<0.01$; Figure $4 \mathrm{~A})$ and $\mathrm{CD} 123^{+}$ DCs $(p<0.01$; Figure $4 \mathrm{~B})$ at 6 months of TC exercise compared with at the onset. There was also significant increase in the percentage of CD11 ${ }^{+}$DCs ( $p<0.01$; Figure $4 \mathrm{~A}$ ) and CD123 $3^{+}$DCs ( $p<0.01$; Figure 4B) at 6 -month compared with at 4 -month of TC exercise. The number of CD11 $\mathrm{c}^{+}$DCs (myeloid) (Figure 4A) increased much more dramatically than that of $\mathrm{CD}_{123^{+}} \mathrm{DCs}$ (plasmacytoid) (Figure 4B). The percentages of both $\mathrm{CD}_{12} 3^{+}$(plasmacytoid) DCs and CD11c ${ }^{+}$(myeloid) DCs in CON group did not show any changes during the study period (onset; 4 months; and 6 months).
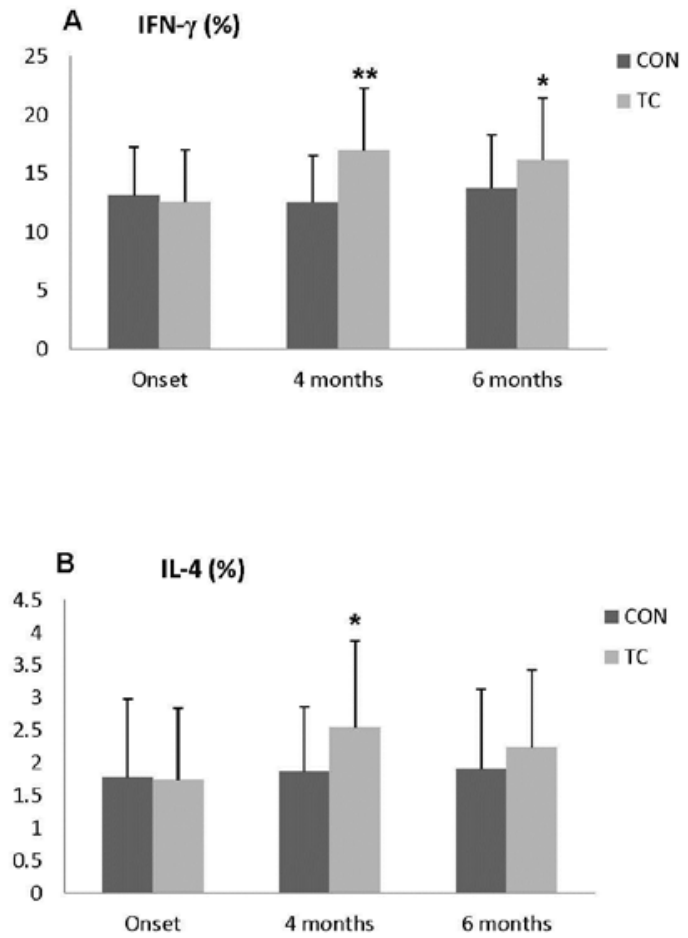

Figure 3: Comparison of the percentages of cytokines IFN-y (A) and IL-4 (B) producing CD4 T cells in the peripheral blood at the onset, 4 months and 6 months during the study period in control (CON) group and Tai Chi (TC) exercise group. Data are presented as Mean \pm SEM. ${ }^{*} p<0.05,{ }^{* *} p<0.01$ as compared with onset of the same group. 


\section{A}
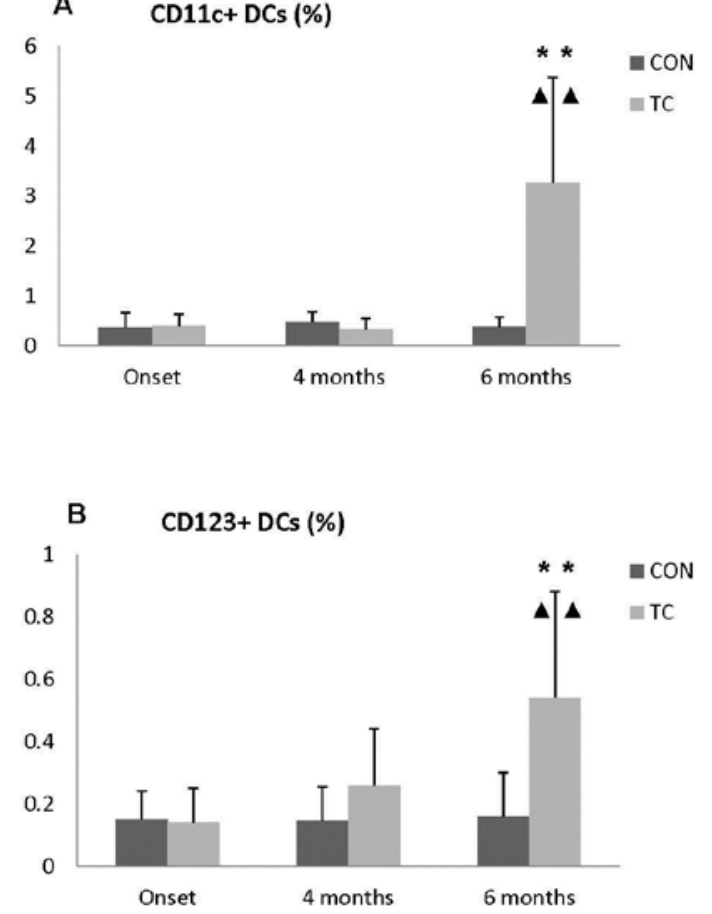

Figure 4: Comparison of the percentages of $\operatorname{CD}_{11 c^{+}}(\mathbf{A})$ dendritic cells (DCs) and $\mathrm{CD}_{123^{+}}$(B) DCs in the peripheral blood at the onset, 4 months and 6 months during the study period in control (CON) group and Tai Chi (TC) exercise group. Data are presented as Mean \pm SEM. ${ }^{* *} p<0.01$ as compared with onset of the same group; $\boldsymbol{\Delta} \boldsymbol{\Delta} p<0.01$ as compared with 4 months.

\section{Discussion}

The human immune system demonstrates degenerative changes with advancing age [17], especially $\mathrm{T}$ cells which demonstrate prominent age-related alterations in distribution and function, such as declined number of circulating Th cells, NKT cells, and DCs, decreased production of Th1 cytokines (IFN- $\gamma$ ) and increased production of Th2 cytokines (IL-4) with aging [2,4,3]. However, the findings of our present study demonstrated that after a 6-month TC exercise program, the percentages of $\mathrm{CD}^{+} \mathrm{T}$ lymphocytes, NK cells, NKT cells, and DCs, along with the $\mathrm{CD}^{+}: \mathrm{CD}^{+}$ratio and cytokines IFN- $\gamma$ and IL-4 producing $\mathrm{T}$ cells, significantly increased in middle-aged and elderly women.

Many studies have reported exercise-induced changes in the immune function [5]. Changes in exercise-induced immune functions are associated with the exercise type, intensity, and the duration of both the exercise and any intermissions [5]. It was observed that the number of $\mathrm{CD}^{+} \mathrm{T}$ cells decreased while the number of $\mathrm{CD} 8^{+} \mathrm{T}$ cells significantly increased, resulting in a decreased $\mathrm{CD} 4^{+}: \mathrm{CD}^{+}$ratio, in seven middleand long-distance runners undergoing four-week intensive training after 36 hours of rest [18]. After a bout of strenuous and prolonged exercise $(>1.5 \mathrm{~h})$, the number of circulating $\mathrm{T}$ lymphocytes decreased below preexercise levels for several hours after exercise, with a decreased $\mathrm{CD}_{4}^{+} /$ $\mathrm{CD}^{+}$ratio [19]. Excessive training can cause significant drop in NK cell number, leading to immune suppression [20]. However, our present work and some previously published studies showed that moderate physical exercise improved immune function [21,22]. A 6-month supervised exercise training program led to nominal increases in some aspects of immune function in previously sedentary elderly [22]. While others reported that NK cell activity increased by $33 \%$ after moderate intensity training for 16 weeks in the elderly population [23], and increased by $57 \%$ in a group of middle-aged women after six weeks of moderate intensity exercise training $\left(60 \% \mathrm{VO}_{2} \max \right)$ [24]. Yeh et al. [14] reported that after 12 weeks of TC exercise, transcription factor T-bet as well as expression of Th1/Th2/T regulatory (Treg) cells significantly increased in type 2 diabetes patients. So far, there have been no studies reporting changes in the age-induced Th1/Th2 immune imbalance after regular long-term Tai Chi exercise. The results of our present study demonstrated for the first time that regular TC exercise appears to favor improvement of Th1 immune responses in middle-aged and elderly women and the percentage of NKT cells and CD11c ${ }^{+}$DCs significantly increased after 6-month regular TC exercise as compared to the control group.

Th1 cytokines, of which IFN- $\gamma$ is typical, support cell-mediated inflammatory reactions by activating cytotoxic and inflammatory functions; while Th2 cytokines, of which IL-4 is typical, support humoral immune responses [25]. Th1 and Th2 cytokines are mutually inhibitory for the differentiation and effector functions of the reciprocal phenotype [26]. IFN- $\gamma$ selectively inhibits proliferation of Th2 cells, and IL-4 and IL-10 inhibit cytokine synthesis by Th1 cells [26]. A number of studies have shown that physical exercise affects Th1 and Th2 immune responses as well as the balance between these responses. Excessive or exhaustive exercise has been reported to induce exercise-related immunosuppression via altering the Th1/Th2 balance by decreasing the percentage of circulating Th1 lymphocytes, with increase or no change in Th 2 cells; and also by decreasing IFN- $\gamma$ production and increasing IL-4 production resulting in a decreased IFN- $\gamma / \mathrm{IL}-4$ ratio [6,27-29]. However, 2-month endurance training of moderate intensity promoted IFN- $\gamma$ production in moderately trained athletes [30], and 6 months of moderate combined (endurance and resistance) training increased spontaneously CD28 expressing Th cells and mitogen-stimulated IFN- $\gamma$ producing Th1 cells in elderly subjects [31]. Consistent with these findings, our present study showed that after 6-month regular TC exercise, the percentages of IL- 4 and IFN- $\gamma$ producing T cells significantly increased, and IFN- $\gamma$ producing $\mathrm{T}$ cells were up-modulated more dramatically than IL-4 producing $\mathrm{T}$ cells. These results suggest that long-term TC exercise can up-regulate Th cell-mediated immune responses and promote the switch of the focus of the immune system from humoral immunity to cell immunity, resulting in a higher Th1type immune response (Th1 dominance) and therefore enhancing antiviral function. However, the mechanism by which TC modulates the Th immune responses and the Th1/Th2 balance remains unclear.

CD1d-restricted NKT cells expressing both invariant T-cell receptors and NK cell receptors are an important immunoregulatory subset of $\mathrm{T}$ lymphocytes, and they play an important role not only in immune defense and surveillance, but also in regulating the immune balance [16]. Activated NKT cells are involved in immune differentiation of Th1 and Th2 cells, and in the switch of the immune response in the opposite direction, i.e., towards a Th1-type response [16]. Most recently, we investigated the relationship between NKT cells and the Th1/Th2 lymphocyte imbalance after overtraining and excessive exercise, and showed that -galactosylceramide played an important modulatory role in the exercise-induced Th1/Th2 lymphocyte imbalance, which may correlate with NKT immunoregulatory cells [32]. It was reported that not only the NKT cell function depends on stimulation and the microenvironment in the initial stages of the immune response, but also the NKT activation signal is transmitted by the specific type of APCs, such as DCs [33].

DCs are the most important and potent APCs, priming the primary 
immune response [34]. Two distinct DC subsets, myeloid DCs (mDC, also called Type 1 DCs, DC1), and plasmacytoid DCs (pDC, also called Type 2 DCs, DC2) that may produce different outcomes after their interaction with $\mathrm{T}$ lymphocytes, have been identified in humans [34,35], DC1 (identified as $\mathrm{CD} 11 \mathrm{c}^{+} \mathrm{CD} 123^{-}$) subsets induce Th1 cell differentiation by the secretion of IL-12. DC2 (identified as CD11 $\mathrm{c}^{-}$ CD123+) subsets secrete mainly IL-10, which induces initial T cells to differentiate into Th2 cells, resulting in immune tolerance. On the basis of these distinct properties of the DC subtypes, mDCs and pDCs are considered to be specialized APCs inducing a Th1 and Th2 response, respectively. Exercise has been reported to induce a significant increase in DC numbers and modulate myeloid DC differentiation and maturation in rats [36,37]. The findings of our present study demonstrated that $\mathrm{TC}$ exercise promotes $\mathrm{CD} 11 \mathrm{c}^{+} \mathrm{DCs}$ and $\mathrm{CD} 123^{+}$ DCs, with the change in $\mathrm{CD} 11 \mathrm{c}^{+} \mathrm{DCs}$ being more dramatic, suggesting that TC exercise facilitates the induction of Th1 cell differentiation.

As the most powerful APCs, DCs can activate resting NKT cells in vivo, present antigen peptide and provide a co-stimulus signal for NKT cell sensitization, activation and amplification [38]. It was shown that DCs produce high levels of co-stimulus molecules to activate $\mathrm{T}$ cells, after combining DCs and T cells to mediate the Th1 response by secreting large amounts of IL-12, helping to eliminate tumors [39]. Others reported that exogenous or endogenous IL-12 induces a progressive decrease in the number of liver NKT cells producing IL4, thus supporting the development of Th1 immune responses [38]. However, immature DCs do not induce Th cell differentiation, and IFN- $\gamma$ mainly induces immature DC differentiation to DC1 cells. The increased percentage of NKT cells enhanced IFN- $\gamma$ secretion, promoting DC1 production and possibly favoring the development of Th1 immune responses. Therefore, NKT cells and DCs demonstrate reciprocal interactions and cooperatively regulate $\mathrm{Th}$ immune differentiation. Our results suggested that TC-induced changes in the Th1 and Th 2 immune responses were related to immune modulation of NKT cells and DCs, and their reciprocal interactions with each other.

In conclusion, our present study has shown that a six-month regular TC exercise program significantly improved immune function in middle-aged and elderly women. The $\mathrm{CD} 4^{+}: \mathrm{CD} 8^{+}$ratio showed a significant increase, and the percentages of NKT cells, CD11 ${ }^{+}$DCs and CD123 $3^{+}$DCs, as well as the percentages of cytokine IFN $-\gamma$ producing $\mathrm{T}$ cells were also significantly increased. The percentage of CD11 $\mathrm{c}^{+} \mathrm{DC}$ was increased more dramatically than that of $\mathrm{CD} 123^{+} \mathrm{DC}$. We conclude that regular TC exercise can improve age-associated immune imbalance and promote the development of Th1 immune responses, and these changes may be related to the immune modulation of NKT cells and DCs and their reciprocal interactions with each other. Therefore, regular TC exercise has beneficial effects of reversing the age-associated immunosenescence in middle-aged and elderly people.

\section{Acknowledgements}

The authors thank Dr. Lai Wei (National Eye Institute, and National Center for Complementary and Alternative Medicine, National Institutes of Health, USA) for critically reading the manuscript. This study was supported by grants from the Shanghai Pujiang Program, the Shanghai Natural Science Foundation (No. 07ZR14103) and the Shanghai Leading Academic Discipline Project (No. T0902). Appreciation is also extended to all participating staff and subjects, whose cooperation made this study possible.

\section{References}

1. Pawelec G, Solana R (1997) Immunosenescence. Immunol Today 18: 514-516

2. Alberti S, Cevenini E, Ostan R, Capri M, Salvioli S, et al. (2006) Age-dependent modifications of Type 1 and Type 2 cytokines within virgin and memory CD4+ T cells in humans. Mech Ageing Dev 127: 560-566.

3. Ernst DN, Weigle O, Hobbs MV (1995) Aging and lymphokine gene expression by $T$ cell subsets. Nutr Rev 53: S18-S25.

4. Della Bella S, Bierti L, Presicce P, Arienti R, Valenti M, et al. (2007) Peripheral blood dendritic cells and monocytes are differently regulated in the elderly. Clin Immunol 122: 220-228.

5. Gleeson M (2007) Immune function in sport and exercise. J Appl Physiol 103 693-699.

6. Lancaster GI, Halson SL, Khan Q, Drysdale P, Wallace F, et al. (2004) Effects of acute exhaustive exercise and chronic exercise training on type 1 and type 2 T lymphocytes. Exerc Immunol Rev 10: 91-106.

7. Zaldivar F, Wang-Rodriguez J, Nemet D, Schwindt C, Galassetti P, et al. (2006) Constitutive pro- and anti-inflammatory cytokine and growth factor response to exercise in leukocytes. J Appl Physiol 100: 1124-1133.

8. Hinton JR, Rowbottom DG, Keast D, Morton AR (1997) Acute intensive interval training and in vitro t-lymphocyte function. Int J Sports Med 18: 130-135.

9. Gleeson M, Bishop NC (2005) The T cell and NK cell immune response to exercise. Ann Transplant 10: 43-48.

10. Shore S, Shinkai S, Rhind S, Shephard RJ (1999) Immune responses to training: how critical is training volume? J Sports Med Phys Fitness 39: 1-11.

11. Davis JM, Murphy EA, Brown AS, Carmichael MD, Ghaffar A, et al. (2004) Effects of moderate exercise and oat beta-glucan on innate immune function and susceptibility to respiratory infection. Am J Physiol Regul Integr Comp Physiol 286: R366-372.

12. Li JX, Hong Y, Chan KM (2001) Tai chi: physiological characteristics and beneficial effects on health. $\mathrm{Br} \mathrm{J}$ Sports Med 35: 148-156.

13. Yeh $\mathrm{SH}$, Chuang H, Lin LW, Hsiao CY, Eng HL (2006) Regular tai chi chuan exercise enhances functional mobility and CD4CD25 regulatory $\mathrm{T}$ cells. $\mathrm{Br}$ Sports Med 40: 239-243

14. Yeh SH, Chuang H, Lin LW, Hsiao CY, Wang PW, et al. (2009) Regular Tai Ch Chuan exercise improves $T$ cell helper function of patients with type 2 diabetes mellitus with an increase in T-bet transcription factor and IL-12 production. $\mathrm{Br} \mathrm{J}$ Sports Med 43: 845-850.

15. Irwin MR, Pike JL, Cole JC, Oxman MN (2003) Effects of a behaviora intervention, Tai Chi Chih, on varicella-zoster virus specific immunity and health functioning in older adults. Psychosom Med 65: 824-830.

16. Kronenberg M, Gapin L (2002) The unconventional lifestyle of NKT cells. Nat Rev Immunol 2: 557-568

17. Weiskopf D, Weinberger B, Grubeck-Loebenstein B (2009) The aging of the immune system. Transpl Int 22: 1041-1050.

18. Nieman DC, Pedersen BK (1999) Exercise and immune function. Recent developments. Sports Med 27: 73-80.

19. Berk LS, Ton SA, Nieman DC, Eby EC (1986) The suppressive effect of stress from acute exhaustive exercise on T-lymphocyte helper/suppressor ratio in athletes and non-athletes. Med Sci Sports Exerc 18: 706-710.

20. Mackinnon LT, Hooper S (1994) Mucosal (secretory) immune system responses to exercise of varying intensity and during overtraining. Int J Sports Med 3: S179-183.

21. Nieman DC (1994) Exercise, upper respiratory tract infection, and the immune system. Med Sci Sports Exerc 26: 128-139.

22. Woods JA, Ceddia MA, Wolters BW, Evans JK, Lu Q, et al. (1999) Effects of 6 months of moderate aerobic exercise training on immune function in the elderly. Mech Ageing Dev 109: 1-19.

23. Crist DM, Mackinnon LT, Thompson RF, Atterbom HA, Egan PA (1989) Physica exercise increases natural cellular-mediated tumor cytotoxicity in elderly women. Gerontology 35: 66-71.

24. Nieman DC, Nehlsen-Cannarella SL, Markoff PA, Balk-Lamberton AJ, Yang H et al. (1990) The effects of moderate exercise training on natural killer cells and acute upper respiratory tract infections. Int J Sports Med 11: 467-473.

25. Mosmann TR, Sad S (1996) The expanding universe of T-cell subsets: Th1 Th2 and more. Immunol Today 17: 138-146

26. Fiorentino DF, Bond MW, Mosmann TR (1989) Two types of mouse T helpe 
Citation: Liu J, Chen P, Wang R, Yuan Y, Li C (2012) Effect of Tai Chi Exercise on Immune Function in Middle-aged and Elderly Women. J Sports Med Doping Stud 2:119. doi:10.4172/2161-0673.1000119

Page 7 of 7

cell. IV. Th2 clones secrete a factor that inhibits cytokine production by Th1 clones. J Exp Med 170: 2081-2095.

27. Haahr PM, Pedersen BK, Fomsgaard A, Tvede N, Diamant M, et al. (1991) Effect of physical exercise on in vitro production of interleukin 1, interleukin 6 , tumour necrosis factor-alpha, interleukin 2 and interferon-gamma. Int J Sports Med 12: 223-227.

28. Lakier Smith L (2003) Overtraining, excessive exercise, and altered immunity: is this a T helper-1 versus T helper-2 lymphocyte response? Sports Med 33: 347-364.

29. Steensberg A, Toft AD, Bruunsgaard H, Sandmand M, Halkjaer-Kristensen J, et al. (2001) Strenuous exercise decreases the percentage of type $1 \mathrm{~T}$ cells in the circulation. J Appl Physiol 91: 1708-1712.

30. Mueller O, Villiger B, O'Callaghan B, Simon HU (2001) Immunological effects of competitive versus recreational sports in cross-country skiing. Int J Sports Med 22: 52-59.

31. Shimizu K, Kimura F, Akimoto T, Akama T, Tanabe K, et al. (2008) Effect of moderate exercise training on T-helper cell subpopulations in elderly people. Exerc Immunol Rev 14: 24-37.

32. Ru W, Peijie C (2009) Modulation of NKT cells and Th1/Th2 imbalance after alpha-GalCer treatment in progressive load-trained rats. Int J Biol Sci 5: 338343.
33. Wesley JD, Robbins SH, Sidobre S, Kronenberg M, Terrizzi S, et al. (2005) Cutting edge: IFN-gamma signaling to macrophages is required for optimal Valpha14i NK T/NK cell cross-talk. J Immunol 174: 3864-3868.

34. Banchereau J, Briere F, Caux C, Davoust J, Lebecque S, et al. (2000) Immunobiology of dendritic cells. Annu Rev Immunol 18: 767-811.

35. Rissoan MC, Soumelis V, Kadowaki N, Grouard G, Briere F, et al. (1999) Reciprocal control of $T$ helper cell and dendritic cell differentiation. Science 283: 1183-1186.

36. Chiang LM, Chen YJ, Chiang J, Lai LY, Chen YY, et al. (2007) Modulation of dendritic cells by endurance training. Int J Sports Med 28: 798-803.

37. Liao HF, Chiang LM, Yen CC, Chen YY, Zhuang RR, et al. (2006) Effect of a periodized exercise training and active recovery program on antitumor activity and development of dendritic cells. J Sports Med Phys Fitness 46 307-314.

38. Pinzon-Charry A, Maxwell T, López JA (2005) Dendritic cell dysfunction in cancer: a mechanism for immunosuppression. Immunol Cell Biol 83: 451 461.

39. Villadangos JA, Heath WR (2005) Life cycle, migration and antigen presenting functions of spleen and lymph node dendritic cells: limitations of the Langerhans cells paradigm. Semin Immunol 17: 262-272. 